Lily O. Agu

Christopher University, Mowe, Nigeria

Information Impact:

Journal of Information and Knowledge Management 2017, Vol. 8 (4) Pg 123 - 136

ISSN: $2141-4297$ (print)

ISSN: 2360 - 994X (e-version)

www.informationimpact.org

\begin{abstract}
Information is becoming a strategic resource. It is an existing prospect for the information professional to add real value to information and contribute more directly to an organization's strategic decision making. Public organizations are using information to harness their resources. This study is aimed at exploring the various benefits of information management in an organization. Information management is the management of organizational processes and systems that acquire, create, organize, distribute, and use information. This paper looks at the information resource management plan and why it is necessary for the growth of the business. Useful recommendations on the need to include information resource management in the overall organizational plan were made.
\end{abstract}

Keywords: information management, information management, organization, strategic planning

\title{
Introduction
}

In the last three to four years, organizations have witnessed the evolution of what used to be basic, standalone inventory management techniques and tools into a complex and wide-ranging management system for enterprise IT asset management and control. Managing the procurement, configuration, deployment, and financial information related to the organization's IT assets required a holistic approach which has come to be known as Infrastructure Resource Management (IRM) ( IBM limited, 2003). Information is organized and communicated data. Reports created from intelligent database queries result in information, for example a result reporting on a specific income group in a particular area provides information that can be communicated to the sales force (Jacques, 2001).

Most organizations have an abundance of information upon which to draw. Unfortunately, if the infrastructure does not provide for the effective creation, use, management, access and delivery of relevant data, the organization will be totally frustrated in its efforts to capitalize on its base of information. Fragmented automation efforts, unilateral commitment to mainframe-based applications, incompatible proprietary hardware platforms, disparate software, and inaccessible data do not satisfy the need for information systems to be an essential, indispensable and strategic component of service delivery and no longer satisfy the business and service goals of many organizations. A revised approach to planning that recognizes the

Information Impact | Journal of Information and Knowledge Management 
relationship between business planning and technical infrastructure is needed. It is critical that this approach address the requirement for:

- $\quad$ Satisfying customer needs;

- $\quad$ responding to changing organizational structures;

- $\quad$ taking advantage of open system concepts;

- $\quad$ adhering to industry standards;

- $\quad$ providing distributed, coordinated and accessible hardware, software and data resources;

- $\quad$ supporting redesigned processes;

- $\quad$ responding to changing requirements;

- $\quad$ being easy to use; and

- $\quad$ Recognizing the significance of data as a corporate resource.

\section{Overview of information management}

Information management is the discipline that analyzes information as an organizational resource. It covers the definitions, uses, value and distribution of all data and information within an organization whether processed by computer or not. It evaluates the kinds of data/information an organization requires in order to function and progress effectively. Information can be complex because business transactions often impact every area within a company. It must be analyzed and understood before effective computer solutions are developed. Information management (IM) is the harnessing of the information resources and information capabilities of the organization in order to add and create value both for itself and for its clients or customers. In this view, IM is a continuous cycle of five closely related activities:
* identification of information needs;
* acquisition and creation of information;
* organization and storage of information;
* information dissemination;
* Information use.

The idea underlying IM is that just as an organization purposefully and systematically manages its human resources or financial assets, it should do likewise for its information resources and processes. All the classic functions of managing an organizational activity apply to IM as well:

Information Impact | Journal of Information and Knowledge Management 
defining goals, providing leadership, developing policies, allocating resources, training staff, evaluation and feedback.

Information Resources Management (IRM) is an emerging discipline that helps managers assess and exploit their information assets for business development. It draws on the techniques of information science (libraries) and information systems (IT related). It an important foundation for knowledge management in that it deals systematically with explicit knowledge. Knowledge centers often play an important part in introducing IRM into an organization. (Information Resources Management insights, No.8)

Information Resource Management (IRM) is a core competency in an Information-Age enterprise. This function directly supports the strategic business objectives through applying management principles to the data resource. It establishes and assures information policies, standards and processes for managing the organization's data, information and knowledge as strategic business resources. IRM is a philosophical and practical approach to managing government information.

Information is regarded as a valuable resource which should be managed like other resources, and should contribute directly to accomplishing organizational goals and objectives. IRM provides an integrated view for managing the entire life-cycle information, from generation, to dissemination, to archiving and /or destruction, for maximizing the overall usefulness of information, and improving service delivery and program management.

IRM views information and Information Technology. As an integrating factor in the organization, that is, the various organizational positions that manage information are coordinated and work together toward common ends. Further, IRM looks for ways in which the management of information and the management of Information Technology are interrelated, and fosters that interrelationship and organizational integration.

IRM includes the management of

(1) The broad range of information resources, e.g., printed materials, electronic information, and microforms,

(2) The various technologies and equipment that manipulate these resources, and

(3) The people who generate, organize, and disseminate those resources. Overall the intent of IRM is to increase the usefulness of government information both to the government and to the public.

The concept of Information Resource Management (IRM) is quite simple: to inventory and control all of the resources needed to satisfy the information needs of an enterprise. Information Impact | Journal of Information and Knowledge Management 
This includes:

- Data components (data elements, records, files, databases, etc.),

- $\quad$ System components (systems, business processes, procedures, programs, etc.), and

- Business components (functions, jobs, human and machine resources, skills, objectives, and projects).

To implement IRM, technology was introduced over the years, starting with the data dictionaries of the 1970s, which evolved into more robust products referred to as "Repositories" that included a manifest of all information resources and how they are interrelated. An IRM Repository, therefore, represents a centralized consolidation of the whereabouts of all corporate information resources, regardless of where used or how stored, including corporate records. For example, it is equally concerned with the information resources as maintained in manual files as it is with those as maintained by the computer. As such, an IRM Repository bridges manual were processing to automate processing.

IRM requires standardization and discipline. In order to implement a centralized facility to share and reuse resources, agreement must be reached in terms of the standard components to be defined, their attributes, and how they relate to other components. This also requires standard processes (methodologies) for developing systems so they can be assembled in a consistent and predictable manner. Regrettably, it is fallacious to believe there are any standards in the IT community and, as a result, most IT shops consist of mavericks with different interpretations of how to address systems development. Concepts such as standardization and discipline are steadfastly resisted.

IRM requires long-term thinking, which is the exception as opposed to the rule in most companies. The true benefits of sharing and reusing resources will not be realized immediately. Instead, it is an investment in the future. Companies will benefit the moment they start to share and reuse information resources from one project to the next. However, the real payoff is when the IRM Repository matures, and components are reused repeatedly.

For some purposes, IRM can be described as a management practice, supported by software and processes. IRM is a multidisciplinary and strategic approach to managing IT assets throughout a defined lifecycle from procurement through disposition.

Some of the same basic information can be enhanced with information for maintenance, deployment all throughout the life of the asset. This service and warranty information is useful for managing the physical condition of the asset. Finally, up-to-date configuration status information can be maintained including hardware and software configurations, upgrades, Information Impact | Journal of Information and Knowledge Management 
locations, and other information useful for Help Desk, Install Move Add Change (IMAC) and Change Management.

The goal is to build and maintain a repository of useful information about all assets that can be used to effectively manage those assets in different ways, and to make that information available to other key business and management processes. In this way, configuration and warranty information can, for example, be made available to the incident management process, enabling an effective Service Desk and efficient dispatch activity. Sharing the data improves the efficiency and effectiveness of all the processes necessary for IT, IT is an ongoing, intensive process that when planned strategically, helps organizations realize an immediate return on their investment.

Gartner Group, through its study of Asset Management Best Practices says that, "IT asset management is 80 process and 20 percent tools and that ....IT asset management is more than a tool, and it is also more than integrating tools and counting "things." IT asset management is the cohesive merging of the physical, financial and contractual attributes of an asset to enable the delivery of cost-efficient, timely business solutions. IT asset management spans the life cycle of an asset and thus has various life cycle interdependencies and information flows by and between multiple business areas."(O'brien, 2002). While software is required, software vendors agree that the key to Asset Management system success is in the process.

"Asset Management is an enterprise-wide strategic initiative. In order for a company to fully benefit from this process, it must involve all organizational levels. It is an ongoing, intensive process that when planned strategically, helps organizations realize an immediate return on their investment." (Peregrine systems, 2001)

The fundamental objective of IRM is to ensure that an organization's information systems support its strategic direction and business plans and enhance the quality, applicability, accessibility and value of the information resources of the enterprise. Its success in an organization is dependent on the acceptance of four fundamental principles: (Strategic Planning for Information Resource Management issued by the International Federation of Malaysian accountants)

An effective IRM program provides for continuously scanning the environment for opportunities that could drive the direction of an organization's business. Information technology planners must have a strategic view on how information systems can increase the opportunities available to an organization and also how to extend traditional business boundaries to include information resource links with customers and suppliers. David Norton points out in "Stage by Stage" (Norton, 1989) that "Traditional boundaries are meaningless. In the organizations of the future, the basic components will be the same but the boundaries of the system will differ as will the Information Impact | Journal of Information and Knowledge Management 
relationships of the internal parts. "He continues, citing specific examples" ...in each case, a strategic advantage was gained by redefining the traditional boundaries of the business. American Airlines and American Hospital Supply extended their franchises to include the customers (or their intermediaries) at the time of purchase. IBM, Otis Elevator and General Motors extended their franchises to include their aftermarket for service. Federal Express restructured its internal operations to permit 100 percent positive tracking of en route packages.

Organizations must emphasize strategic planning for IRM in order to gain a competitive advantage as they move into an era of increased automation and global competition. Information systems can help streamline business functions, improve managerial decision making, create new products and businesses and enhance relationships with suppliers and customers.

\section{Benefits of IRM}

There are many areas of benefit to organizations, some of which are available in the tools. Implementing "point" solutions can produce some benefits, and indeed, to achieve those benefits, integration may not always be necessary. A look at these benefits in the context of IRM is revealing. The 1990s have produced a dramatic change in the information systems organizational structure and in associated accountabilities. Because the convergence of business strategy and information systems strategy is still evolving, many roles are in transition. Individuals with a thorough grounding in the business of the organization are increasingly required to understand how best to deploy technology. Similarly, individuals with extensive technical knowledge are increasingly being asked to interpret and apply business strategies. However, it is important that the roles and responsibilities associated with IRM be understood and that there is a common agreement on the alation of accountabilities. The architects, developers, user department managers, etc., must work as a team with other stakeholders to manage the opportunity from its inception through to the realization of the business benefits.

Information Resource Management (IRM) takes a broad view of the enterprise and does not focus too narrowly on the requirements of a particular group or department.

An effective strategic IRM plan describes an organization's information requirements and strategies for satisfying them and can yield the following benefits: development of systems that are targeted to support strategic and operational objectives;

increased integration of technologies, which improves the sharing of information across the organization and makes it easier to obtain information for changing decision-making needs;

Information Impact | Journal of Information and Knowledge Management

\section{8}


identification and adoption of appropriate information technology standards, minimizing dependence on specific suppliers of hardware or software; identification of opportunities to improve the relevance and adequacy of information provided and activities performed; a technological infrastructure that will support the strategic business plan; minimization of duplicate, and possibly inconsistent, data and processing capabilities within the organization's portfolio of information systems; prioritization of projects to be implemented; and greater costjustification of system development and maintenance activities.

Since no one tool can completely fulfill the IRM requirements, open standards-based tools must be linked seamlessly. In the on demand business environment, infrastructure must enable, this is extremely important as on demand businesses adopt a service-based orientation. Specific services, such as Web portal-based procurement, must be integrated with the rest of the elements in the IRM.

\section{TEN WAYS TO USE INFORMATION RESOURCE MANAGEMENT TO ADD VALUE TO BUSINESS}

There are ten guidelines with a broad coverage, ranging from developing a strategic role for information to the development of capabilities and the marketing of the information unit. There is a considerable degree of overlap between these guidelines, since many of them support and depend on each other. Below are ten ways to use information resource management as highlighted by Skyrme (1994).

\section{Establishing the Strategic Role of Information}

This is a two stage process: (1) a research and investigation phase that gives you the information you need for (2) articulating your mission and strategy. The first phase requires an assessment of the attitudes of senior management to information and how much they are willing to pay for it. The head of a market research unit was asked how hard it was to justify their existence and budget. He commented: "that it has not been a problem, ever since they spend hundreds of millions of dollars on a new product and then lost market share to the Japanese". This direct link between a large strategic investment and the bottom line delivered a sharp lesson to senior management on the value of competitor intelligence.

Some of the strategic decisions whose successful outcomes depend on the availability of good information include:

- $\quad$ Market selection and targeting

Information Impact | Journal of Information and Knowledge Management 
- New investments

\section{- $\quad$ Location of factories and offices}

- New product development and launch

- $\quad$ Pricing and Promotion

Find out how these decisions are made, what information is used, and from where it is sourced. You may already have data from feedback on how the information you have supplied has helped such processes (if not, you should get it!). Has your organization recently had successes or failures that could be directly attributed to good or bad information? From these investigations you can determine areas of high information leverage where you could play a role. Identify the linkages between information and results. This should then be a cornerstone of your strategy. Use every opportunity to let people, especially senior managers, know about it.

\section{Identify Users Real Needs}

This is the first of the marketing guidelines. It is essentially about market research. Therefore use the methods used by researchers - surveys, interviews, usage analysis. You already have users. Find out how they use your output and again what results and benefits they achieve. One particularly useful way of teasing this out (used, by the way, to justify office automation systems) is to ask what would happen if you did not offer that service.

Getting to senior management users and non-users is an important strand of this activity. You must also learn about their real needs, not the ones they may initially express. Some of these may be psychological needs such as "I want to impress our senior management team with the range of authoritative information I have at my disposal". Too often, information audits approach this activity from the wrong end by asking lots of questions about "information". The starting point should be discussion of a person's role, their organizational context, and what their critical activities and decisions are. One technique that I have found very effective is the use of a semistructured interview recorded on tape

\section{Segment Your Market}

This is the keystone of every marketing strategy - grouping customers into segments with common sets of needs. Too often, information unit providers offer a homogenous service to all. This tends to create averaging, of a mediocre service to everybody, rather than an excellent service to some.

Typically segments may be based on departments, product lines, or industries served. However, one attractive method of segmentation relies on the distinctively different needs of senior Information Impact | Journal of Information and Knowledge Management 
managers involved with strategic decisions, field sales people, and people in headquarters functions, such as product development and marketing. By defining a few distinct segments you can develop different service approaches and perhaps different resourcing and pricing. This will overcome the common pitfalls of a common approach that leads to conflicts between the "urgent" and important"

\section{Create a Unique Product}

Although you are offering a service, it has many features of a product - a look and feel, a function, and often a tangible manifestation (printed or electronic output). Therefore you need to think in ways of how to make this output more attractive. Your users can buy information elsewhere (and probably do). Your challenge is to customize and add value.

A second aspect of improving the service to your customers is to broaden their scope. Look beyond the normal services of a library. Can you get in-house experts to add analysis and comment? Can you organize events around specific themes with outside speakers? Technology can also play an important part. It lets you reach more users effectively, and can reduce your information handling time. Increasingly it makes sense to let users have direct on-line access to information and even to encourage their use of external on-line services.

One caveat, though, is not to undertake activities that can be done as effectively by others or by the users themselves (such as ordering specialist books and journals). One need to package activities as a set of products that are unique and distinctive.

\section{Sales and Marketing}

There is no getting away from it. A successful information unit will sell and market its services. It will have promotional fliers that also serve to inform and educate users. It may well have its own identity and logo. It should also get out and meet customers at their events, such as a sales meeting or the in-house annual research conference. As well as helping the 'selling' it also gains valuable input that helps you develop and improve your services.

Pricing is another aspect of marketing that needs careful attention. Gone are the days when you can continually offer your services for free. Information is valuable - let your clients appreciate that! One approach that can be very effective in a sizeable unit is to allocate different professionals as 'account managers' for different client groups. This helps their own personal development as they will learn to represent the whole of the information unit and not just their own specialist activity.

6. Evaluation and Feedback Information Impact | Journal of Information and Knowledge Management 
Evaluation and feedback will help you fine tune your product offering, and your marketing strategy. It also links back to the first marketing phase that of research, thus completing the management loops. Three simple but effective ways of gaining feedback are: include a feedback sheet with every item you send out; keep it short e.g. 2-3 questions, such as asking how they used the information provided, and how much time and money it saved maintain a call log (even easier with a computerized client data-base); use it to analyze the pattern of demand and identify any patterns over time-publish the results; it generates even more feedback, and also maintains visibility.

\section{Exploit Technology}

One of the best ways to leverage scarce resources is to let technology (and your users) do some of the work for you! Many information professionals will already use information technology quite extensively and it is a theme that has touched upon in several of the earlier guidelines. However, there are certain developments that you need to keep abreast of, and offer opportunities for off-loading work:

- Sales and marketing administration packages to improve client service

- Multimedia and its potential for demand publishing as an alternative to purchasing hardcopy journals

- PC information retrieval packages, such as Idealist that users can use themselves

- The Internet and its search and retrieval tools

- Electronic mail for mass distribution and information centre newsletters

- Computer conferencing as a means of gaining feedback and developing plans and turning information into intelligence

The great benefit of today's technology is that it allows access to library collections from the user's desk top (the 'virtual library'). Networks allow you to promote and deliver your services more easily throughout your organization, and to draw on outside resources. It could well be, if you are in a large organization, that there are multiple information units, rather than a single central one. Networking allows access to common material, pooling of resources and greater opportunities for mutual help and support.

\section{Selective Outsourcing}

One of the current management fashions is that of outsourcing - contracting out of specialist, non-core activities to outside providers. Its attraction is that outside specialists can offer a broader range of skills and knowledge, and generally at a lower cost. However, before outsourcing organizations must think very carefully about what to retain and what to divest. Some recent lessons from the IT world are instructive.

Information Impact | Journal of Information and Knowledge Management 


\section{Information Management in Organizations: An Overview}

Whereas facilities management, systems development and upgrading systems are typically outsourced, what tends to be retained in-house are:

- $\quad$ Policies e.g. for buying

- $\quad$ Standards and quality assurance

- Infrastructure

- User requirements identification

- User support

- $\quad$ Some development

Generally, the more 'commodity-like' the service on offer, the better it is as a candidate for outsourcing. On the other hand the more organization specific or strategic it is, the more the arguments favor retention in-house. Even with outsourcing it is necessary to retain some specialist information skills to select and manage the external contractors.

9. Building Partnerships

Building effective partnerships with clients and suppliers is paramount. There are several means by which partnerships with the business can be strengthened. They operate at three levels:

Organization level - the reporting structure can have a positive influence. An information unit that is a corporate function, rather than embedded within one department is generally better positioned, Also treating it as a separate profit centre. The strategic influence is increased when the head of the information unit report to a member of the board - here it was the director of marketing and strategy.

Teams - there should be teams and task forces that bring information professionals together with business managers. If the account manager approach is adopted, ensure that the information professional becomes an integral part of one of the client's management teams. Also why not have user representatives on your own management team.

Individual - opportunities to improve partnership occur when individuals develop good working relationships with each other. One way of achieving this is through co-location e.g. of an information professional into a user department,say for six months, between a business unit and the information unit.

10. Develop Hybrid Skills

Information Impact | Journal of Information and Knowledge Management 
Although you may have trained as an information professional, to bring improved benefits to the business you will need to broaden your skills i.e. become something of a "hybrid". A hybrid manager (Earl, Michael and Skyrme, David .J .1992) has a mixture of business knowledge and general management skills as well as that of their specialty. Some of the key skills they possess are:

- $\quad$ Knowledge of the industry in which the organization operates

- $\quad$ Awareness of business issues and pressures

- Organization "know-how" and "know-who"

- $\quad$ Communication skills

- Inter-personal skills

Therefore, unless you want to remain a specialist, you should take time out to develop some, if not all, of these skills. This can be achieved by management training, going to industry events and courses, and being assigned on secondment to a business unit.

\section{Summary and conclusion}

From the foregoing, information resource management is very vital for any organization to grow and organizations must also implore information resources strategic plan for their venture to succeed. In summary information resource is the key to make an organization or business to grow. The destiny of any organization lies in the hands of the amount of information reosur4ec they is able to management. A number of guidelines that help to develop this new strategic role have been outlined. They have been based on experience with a marketing approach and a service/customer orientation. They are development processes that rely on activities beyond basic information service provision. Properly implemented these guidelines should improve the strategic positioning and visibility of information units, enhance client satisfaction, be cost effective, and help to anticipate opportunities and threats. Above all, they will works towards securing the prosperous future of the in-house information unit. Following these guidelines, organizations can avoid the risk and capitalize on the opportunity to achieve cost savings and efficiencies, while providing greater services to their end users and preparing for a future where the IRM will be highly autonomic and adaptable.

\section{References}

Adams, Patricia, (2001) Three Tools of an IT Asset Management Program Gartner Group. Information Impact | Journal of Information and Knowledge Management

\section{4}


Custer, Jeffrey A. (1995). The Role of IRM in a Client/Server Environment. Data Base Newsletter

Custer, Jeffrey A. (April).1995.Six Ingredients of a Successful IRM Environment. Data Base Newsletter

Drucker, Peter E. 1988. The coming of the new organization, Harvard Business Review, pp45-53

Earl, Michael and Skyrme, David J.1992 'Hybrid managers'- what do we know about them?' Journal of Information Systems, Vol. 2, pp 169-187

Fisher, Sharon, ( 2001)Asset Management: An Introduction, Gartner Research.

General Architectural Principles was published by the state of North Carolina in early 1994.12

Health Care Financing Administration's Strategic IRM Plan (FY 1996-2000). This is the primary Federal Agency responsible for administering the Medicare program in the United States.

Information Resources Management, Insights No 8 .David Skyrme Associates. Jacques Steyn, Jacques@knowsystems .com

Klinto, K (1968)Danish Technical Information Service , Presentation at FID,3rd general assembly ,Tokyo.

McKay, David T., and Douglas W. Brockway. Building I/T Infrastructure for the 1990s. (Nolan, Norton \& Co., Stage by Stage, 9,3).

Mcmichols, Williams (2003).Sr Infrastructure System Management Consultant. IBM global services

Nonaka, Ikujiro, (1991).The knowledge creating company, Harvard Business Review, pp96-104

Norton, David P.(1989).Whatever Happened to the Systems Approach. Nolan, Norton \& Co., Stage by Stage. 1-12

O’Brien, Frances, (2002) .IT Asset Management Conference: Best Practices. Gartner Group.

Peregrine Systems Market White Paper 2001.“Best Practices in Asset Management”.

Quinn, James brain (1992), intelligent enterprise: a knowledge and service based paradigm for industry, the free press.

Information Impact | Journal of Information and Knowledge Management

\section{5}


Shoup, Larry.(1999). IT Asset Management: The Big Picture, Janus Technologies, Inc., Snyder, B., 2001 “The Hidden ROI of Asset Management”, Meta Group, 11/26/01

Skyrme, David J. (1990).Developing successful marketing intelligence: a case study, Management Decision, Vol 28, No. 1, pp 54-61

Skyrme, David J. (1994).Managing Information, Vol. 1, No. 3, pp. 20-25. Reproduced with the permission of Aslib.

Skyrme, David J.(1995).Information Resources Management. No. 3, Reproduced with the permission of Aslib.

Snyder, William, (2003) Tactical Asset Management Return on Investment, Meta Group, 2/18/2003 as reprinted on Remedy Corp.

Strategic Planning for Information Resource management issued by the International Federation of Malaysian accountants.

Van Den Hoven, John. (1995) Data Base Management, IRM: An Enterprise View of Data. Information Systems Management, 69-72

Walter M, Carlson, (1967).Engineering information for National Defense .New York. Engineers Joint Council.

Willard Nick (1993) Information Resources Management, Aslib. Information, Vol 21,No.5

Information Impact | Journal of Information and Knowledge Management 